\title{
Perancangan Proses Bisnis Menggunakan UML Berdasarkan Fit/Gap Analysis Pada Modul Inventory Odoo
}

Designing Business Process Using UML Based On Fit/Gap Analysis In Odoo Inventory Module

Diterima:

30 Januari 2019

Revisi:

17 Februari 2019

Terbit Online:

12 April 2019

\author{
${ }^{1}$ Riska Sukmawati, ${ }^{2}$ Yudi Priyadi \\ ${ }^{1,2}$, Manajemen Bisnis Telekomunikasi dan Informatika, Universitas \\ Telkom \\ ${ }^{1,2}$ Bandung, Indonesia \\ E-mail: ${ }^{1}$ riskasukma@student.telkomuniversity.ac.id, \\ 2whyphi@telkomuniversity.ac.id
}

\begin{abstract}
Abstrak - Sistem informasi perusahaan yang menjadi andalan saat ini adalah Enterprise Resource Planning (ERP). Adanya perbedaan data sistem dan data riil pada PT OTKA dan Odoo membuat perusahaan perlu melakukan evaluasi agar gap tersebut tidak terus terjadi. Penelitian ini menggunakan Fit/Gap Analysis digunakan untuk membandingkan apakah sistem sudah sesuai harapan perusahaan, kemudian dilanjutkan dengan Failure Mode Effect Analysis (FMEA) untuk memperoleh tingkat Risk Priority Number (RPN). Hasil evaluasi berupa rekomendasi sistem yang digambarkan dengan Unified Modelling Languange (UML) dan mockup User Interface. Data penelitian menggunakan data primer dan data sekunder. Teknik validitas data menggunakan metode triangulasi. Hasil dari penelitian ini PT. OTKA dinilai belum mengimplementasi Odoo dengan maksimal karena persentase kondisi Gap lebih besar dari kondisi Fit. Setelah dilakukan analisis risiko, terdapat dua proses dengan nilai RPN tertinggi, masing-masing sebesar 448 yaitu update stock barang masuk dan keluar otomatis. Maka rekomendasi untuk perusahaan adalah adanya penambahan proses dan aktor khusus yang dapat melakukan pemantauan setiap perpindahan barang.
\end{abstract}

Kata Kunci- Enterprise Resource Planning, Fit/Gap Analysis, FMEA, Unified Modelling Languange, Evaluasi Proses Bisnis

\footnotetext{
Abstract - The company's information system that currently mainstay is Enterprise Resource Planning (ERP). The different data systems and real data at PT OTKA and Odoo make the company need to evaluate so that the gap does not continue. This study uses Fit/Gap Analysis which is used to compare whether the system is in line with company expectations, and then Failure Mode Effect Analysis (FMEA) to obtain the Risk Priority Number (RPN) level. The evaluation results of a system evaluation described by the Unified Modeling Language and mockup User Interface. The research data uses primary and secondary data. The data validity uses the triangulation method. The results of this study is PT OTKA has not implemented the Odoo maximally because the percentage of Gap is greater than the Fit. After risk analysis, two processes with the highest RPN, each of it is 448, which is updating the inventory of goods in and out automatically. So recommendations for companies are the result of special processes and actors who can monitor each goods transfer.
}

Keywords - Enterprise Resource Planning, Fit/Gap Analysis, FMEA, Unified Modeling Language, Business Process Evaluation. 


\section{PENDAHULUAN}

PT. Otka Tekno Aditama sebagai perusahaan penyedia layanan teknologi informasi yang tergolong sebagai perusahaan baru atau startup bisnis, tidak saja menggunakan sistem ERP dalam proses bisnisnya sebagai peningkat kinerja perusahaan, tetapi juga sebagai competitive advantage. Enterprise Resource Planning (ERP) merupakan sistem perusahaan yang mencakup semua fungsi yang ada di dalam perusahaan dan dibuat dalam bentuk modul terpisah, tetapi saling terintegrasi untuk mendukung proses bisnis perusahaan[1].

PT. Otka Tekno Aditama menggunakan ERP berbasis Odoo 10 versi community sebagai sistem pendukung proses bisnisnya. Setiap kegiatan bisnis yang dilakukan OTKA selalu melalui ERP Odoo, dengan kata lain Odoo dapat menjadi backup dokumen bisnis perusahaan, seperti penawaran, order pembelian dan faktur. Penelitian ini akan melakukan evaluasi terhadap implementasi suatu sistem pendukung proses bisnis pada PT. Otka Tekno Aditama dengan Odoo v10 Community. Berdasarkan hasil wawancara pada perusahaan, ditemukan adanya beberapa masalah pada sistem dengan perusahaan, diantaranya yaitu adanya perbedaan jumlah stock barang yang tercatat pada sistem dengan kondisi barang real di Gudang. Perbedaan data tersebut ditemukan pada sistem Odoo v10 Community modul Inventory.

Beberapa penelitian terkait analisis kinerja ERP terhadap perusahaan diantaranya dilakukan oleh M. Isa Wibisono pada tahun 2017 tentang migrasi sistem yang berjalan ke SAP ECC 6.0 menggunakan fit/gap analysis dan analisis risiko FMEA. Pada penelitian tersebut mengusulkan bahwa metode fit/gap analysis dapat menghasilkan identifikasi data atau komponen sistem yang membutuhkan solusi untuk mengurangi risiko pada penerapan sistem informasi enterprise[2]. Mengenai risiko yang disebabkan oleh kesenjangan tersebut, maka diperlukan analisis risiko lebih mendalam mengenai risiko yang akan timbul menggunakan FMEA[3]. Penelitian oleh Perdana pada tahun 2014 mengenai meminimalisasi risiko keselamatan kerja menggunakan metode FMEA yang diintegrasikan dengan TOPSIS untuk mengetahui tingkat terjadinya risiko melalui nilai Risk Priority Index (RPI)[4]. Risiko kecelakaan tersebut digunakan sebagai variable kuisioner untuk mendapatkan nilai severity, occurance dan detection yang selanjutnya melakukan perhitungan TOPSIS untuk mendapatkan nila RPI. Setelah dilakukan perhitungan dengan diagram pareto[5], didapatkan risiko kecelakaan dengan persentase terbesar akan dicari solusi efektif untuk meminimalkan efek risiko yang timbul karena risiko kecelakaan tersebut[6].

Berdasarkan pada studi penelitian yang telah diuraikan, dilakukan kegiatan pengukuran mengenai kesesuaian sistem informasi yang akan digunakan dengan tujuan perusahaan, dan menjadikan alur proses bisnis di PT. Otka Tekno Aditama menjadi alur proses bisnis yang dapat memberikan keuntungan kepada perusahaan serta memberikan rekomendasi dari hasil penelitian. 
INTENSIF, Vol.3 No.2 August 2019

ISSN: 2580-409X (Print) / 2549-6824 (Online)

DOI: https://doi.org/10.29407/intensif.v3i2.12697

Fit/Gap Analysis merupakan alat yang membantu perusahaan dalam membandingkan performa saat ini dengan performa kebutuhan perusahaan yang potensial. Fit/gap analysis didasari oleh dua kondisi yaitu keadaan terpenuhi dan keadaan potensial. Dengan melakukan analisa fit dan gap perusahaan diharapkan mampu memaksimalkan performa yang ada hingga menuju ke potensi dan sumber daya yang seharusnya dapat dipenuhi[7]. Latar belakang masalah dan kebutuhan dari PT. OTKA, yang membutuhkan solusi untuk penyelesaian masalah sistem, dengan cara pengembangan fitur (enhancement) dan tambahan fitur baru (add-on) untuk mengurangi risiko pada penerapan integrasi sistem informasi. Terkait dengan risiko yang disebabkan dari kesenjangan tersebut, maka diperlukan Analisis Risiko (Risk Analysis) lebih mendalam mengenai risiko yang akan ditimbulkan menggunakan Failure Mode Effect Analysis (FMEA). Analisis risiko menggunakan FMEA yang diimplementasikan untuk menganalisis potensi masalah keandalan atau peristiwa yang tidak diinginkan untuk mengambil tindakan untuk mengatasi masalah, sehingga dapat meningkatkan kehandalan sistem melalui desain [8]. Selain itu FMEA mampu menilai, mengelola, dan mengurangi risiko dari kegagalan produk, proses, layanan pada sistem enterprise[9].

Selanjutnya, untuk saran penelitian akan digambarkan melalui alur proses bisnis baru dengan model Unified Modelling Language (UML) dengan perancangan User Interface pada modul inventory. Unified Modeling Language (UML) adalah alat yang lebih efisien untuk pemodelan. Selain itu, menggunakan pendekatan UML dapat membantu memvisualisasikan, menentukan, membuat dan mendokumentasikan artefak sistem secara efektif yang bermanfaat bagi berbagai pemangku kepentingan aplikasi[10]. Saat ini, sebagian besar para perancang sistem informasi dalam menggambarkan informasi, memanfaatkan UML diagram dengan tujuan utama untuk membantu tim proyek berkomunikasi, mengeksplorasi potensi desain, dan melakukan validasi desain arsitektur perangkat lunak atau pembuat program[11]. Dari sekian banyak komponen diagram yang terdapat pada UML, untuk penelitian ini digunakan lima komponen UML dalam membuat perancangan proses bisnisnya, yaitu: Use Case Diagram, Use Case Scenario, Activity Diagram, Sequence Diagram, dan Class Diagram[12].

\section{METODE PENELITIAN}

Kerangka pemikiran pada penelitian ini, dimulai dari identifikasi permasalahan yang terjadi pada PT OTKA, setelah rumusan masalah dibuat, kemudian ditentukan tujuan dan manfaat penelitian. Untuk pengumpulan data ada tiga kegiatan, yaitu: studi dokumentasi, observasi lapangan dan studi pustaka. Setelah semua data dikumpulkan, kemudian data diolah dengan Fit/Gap Analysis dan diteruskan oleh analisis risiko FMEA. Setelah itu, dibuat rekomendasi berdasarkan hasil pengolahan data yang digambarkan dengan Unified Modelling Languange 
(UML), beserta dukungan mockup user interface. Selanjutnya, kesimpulan dan saran dibuat berdasarkan hasil analisis dan rekomendasi yang telah dilakukan pada proses-proses sebelumnya. Silahkan Cermati Gambar 1.

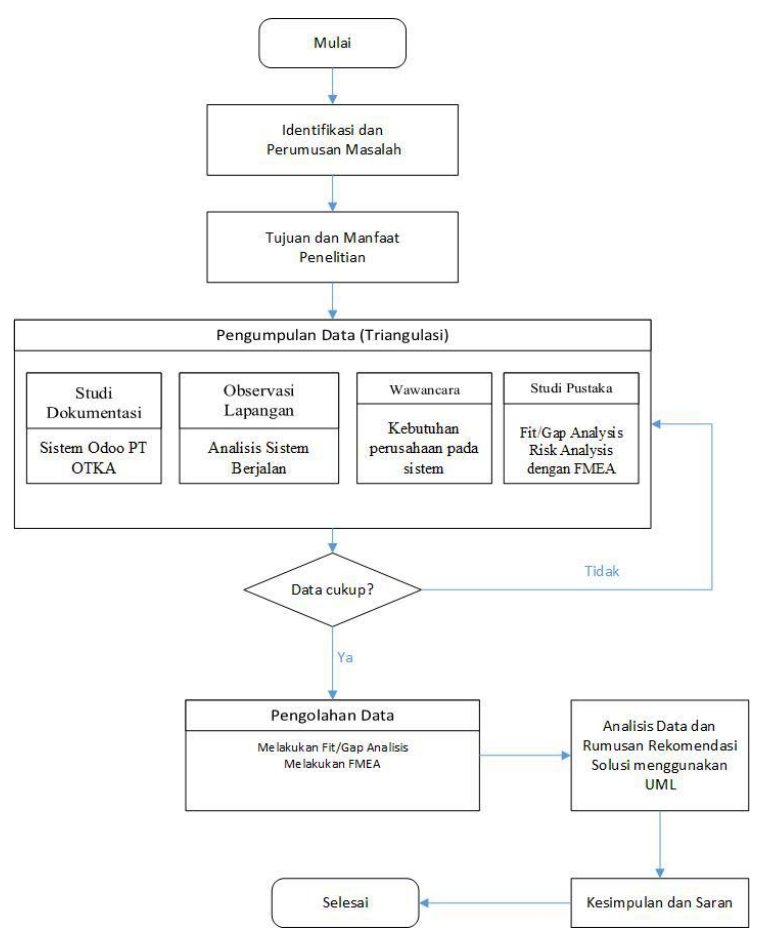

\section{Gambar 1. Kerangka Pemikiran Penelitian}

Metodologi penelitian dilakukan sebagai berikut:

1. Karakteristik Penelitian

Penelitian ini menggunakan metode kualitatif. Metode penelitian kualitatif merupakan metode penelitian yang digunakan untuk meneliti pada kondisi obyek yang alamiah, dimana peneliti adalah instrumen kunci. Tujuan penelitian merupakan penelitian deskriptif. Tipe penyelidikan penelitian yang akan dilakukan adalah Komparatif. Keterlibatan peneliti pada penelitian ini ialah peneliti tidak melakukan intervensi data yang diperoleh. Maka data yang didapatkan ialah data asli tanpa perubahan apapun. Jenis unit analisis yang dilakukan dalam penelitian ini adalah organisasi, dikarenakan penelitian ini menganalisis perilaku yang dilakukan oleh organisasi dalam menerapkan sistem pendukung proses bisnisnya. Waktu pelaksanaan yang dilakukan dalam penelitian ini termasuk jenis cross sectional karena penelitian hanya dilakukan satu kali dan tidak berulang.

\section{Teknik Pengumpulan Data}

Wawancara dengan cara pengambilan sampel sumber data yang dilakukan secara purposive dan snowball serta teknik pengumpulan data dengan triangulasi (gabungan) dimana analisis data bersifat induktif atau kualitatif dan menghasilkan makna generalisasi[13]. Studi dokumentasi 
INTENSIF, Vol.3 No.2 August 2019

ISSN: 2580-409X (Print) / 2549-6824 (Online)

DOI: https://doi.org/10.29407/intensif.v3i2.12697

dengan pengumpulan dokumen catatan peristiwa yang diamati sebagai pelengkap dari metose observasi dan wawancara dalam penelitian kualitatif[13]. Observasi yang dilakukan adalah pengamatan langsung pada perusahaan dengan mengamati sistem kerja menggunakan alat bantu perekam dan kamera. Lokasi PT. Otka Tekno Aditama yang menjadi objek dalam penelitian ini yang beralamat di Gedung Pembina Graha, Lt. 2 no. 34, Jl. D. I. Panjaitan No 45, Jatinegara, Jakarta Timur. Studi pustaka dilakukan untuk mendapatkan pemahaman komprehensif tentang kerangka kerja fit/gap analysis dan failure mode and effect analysis, konsep dan tahapan pengembangan sistem informasi. Teori-teori pendukung tersebut diperoleh dari buku, jurnal, ebook dan penelitian sebelumnya.

3. Validitas

Teknik pengumpulan data yang digunakan pada penelitian ini adalah teknik triangulasi yaitu dengan mengumpulkan data dengan berbagai macam teknik sekaligus menguji kredibilitas data. Data yang dinyatakan valid melalui triangulasi akan memberikan keyakinan terhadap peneliti tentang keabsahan/keaslian datanya

\section{HASIL DAN PEMBAHASAN}

\section{Existing System}

Penyajian proses bisnis yang sedang terjadi pada PT Otka Tekno Aditama menggunakan activity diagram. Pada diagram ini terdiri dari tiga actor, yaitu: Client, OTKA dan Vendor.

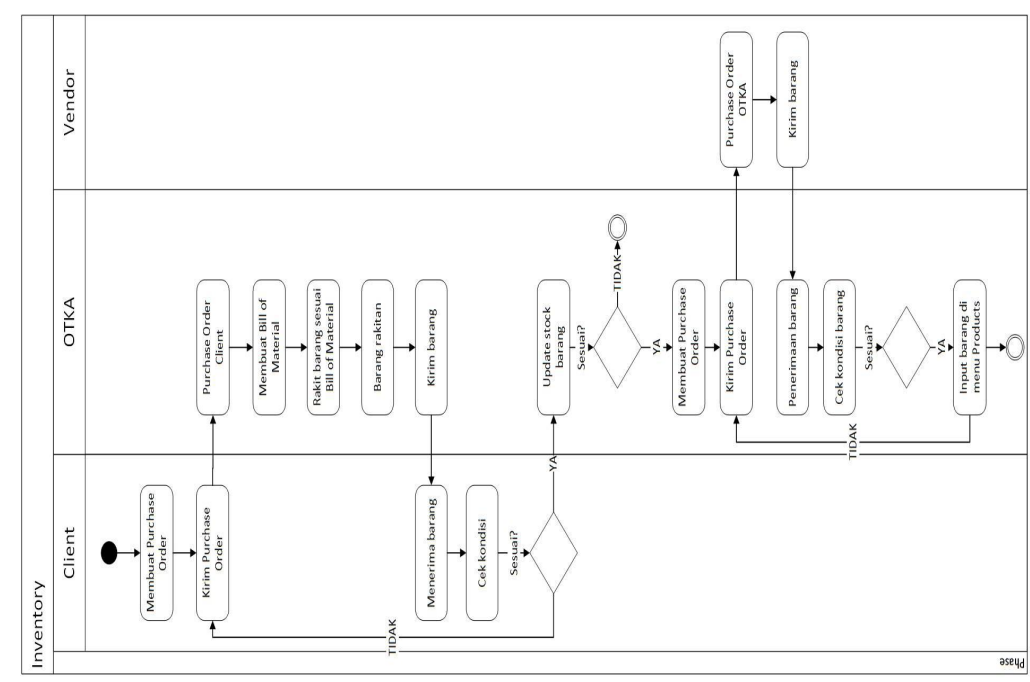

Gambar 2. ACTIVITy DiaGRam Proses Bisnis yang Sedang Berlangsung

Proses bisnis bagian Inventory yang dijalani oleh OTKA, yaitu dimulai ketika Client membuat Purchase Order dan dikirimkan ke OTKA. Kemudian OTKA membuatkan Bill of Material. Setelah itu OTKA merakit barang sesuai dengan Bill of Material. Setelah selesai dirakit, maka barang dikirim ke client. Setelah itu, client menerima barang yang dikirim dari OTKA, lalu 
cek kondisi barang apakah sudah sesuai dengan dokumen Purchase Order. Jika tidak sesuai maka client mengirim Purchase Order lagi, apabila sesuai maka sudah selesai untuk proses ini dan OTKA harus update stock barang yang sudah keluar tersebut. Apabila stock barang sudah habis, maka OTKA akan mengirimkan Purchase Order ke vendor untuk membeli barang itu. Kemudian vendor menerima Purchase Order, setelah itu mengirim barang ke OTKA. Barang yang sudah sampai di cek terlebih dahulu apakah sesuai dengan Purchase Order yang dikirim sebelumnya, jika tidak sesuai maka proses diulang dari pengiriman Purchase Order, jika sesuai maka proses selesai.

\section{Fit/Gap Analysis}

Berdasarkan hasil wawancara, maka PT OTKA menentukan delapan user requirement yang dibutuhkan perusahaan pada modul Inventory. Terdapat empat user requirement pada bagian Receipts, tiga user requirement bagian Delivery Order, dan satu user requirement bagian Manufacturing. Hasilnya menunjukkan bahwa, pada bagian Receipts, user requirement yang menunjukkan kondisi Fit adalah 25\% dan kondisi Gap sebesar 75\%. Kemudian pada bagian Delivery Order terdapat user requirement mengalami kondisi Fit sebesar 33,3\%, kondisi Partial Fit sebesar 33,3\% dan kondisi Gap sebesar 33,3\%. Pada bagian Manufacturing terdapat user requirement mengalami kondisi Partial Fit sebesar 100\%.

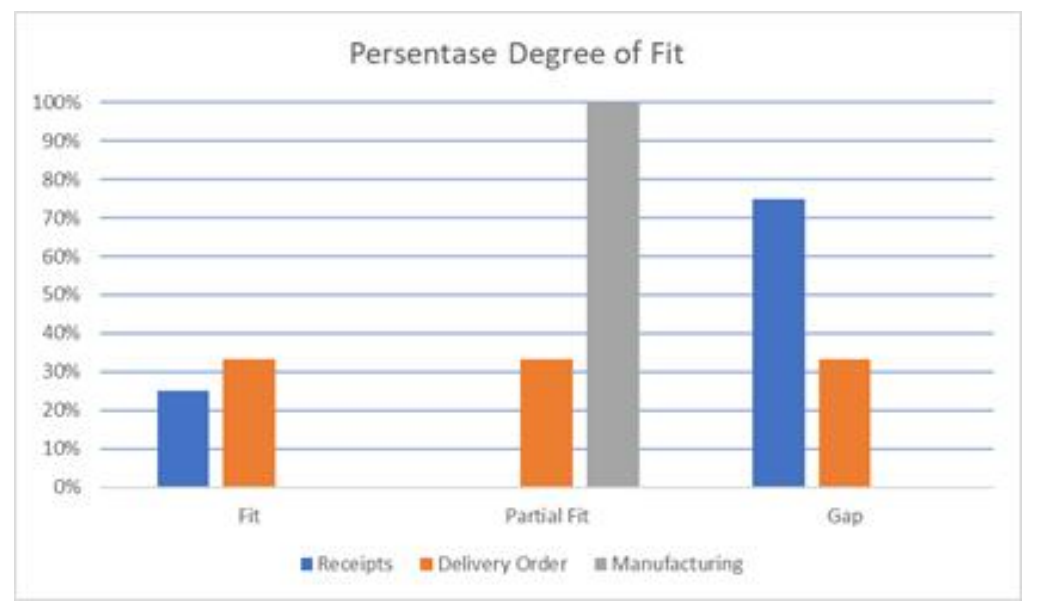

Gambar 3. PERSENTASE DEGREE OF FIT

Setelah mendapatkan nilai degree of fit, langkah berikutnya adalah menentukan Ranking Requirement pada setiap proses, dengan memberikan peringkat High, Medium dan Low. Untuk (i) High menunjukkan tingkat kebutuhan yang sangat penting bagi proses bisnis. (ii) Medium menunjukkan kebutuhan ketika dipenuhi akan meningkatkan proses bisnis. (iii) Low menunjukkan kebutuhan yang jika dipenuhi dapat menambah nilai meskipun kecil (minor value) bagi proses bisnis. Berikut ini adalah tabel hasil Ranking Requirement. Silahkan cermati tabel 1. 
INTENSIF, Vol.3 No.2 August 2019

ISSN: 2580-409X (Print) / 2549-6824 (Online)

DOI: https://doi.org/10.29407/intensif.v3i2.12697

Tabel 1. Ranking ReQuirements Receipts, Delivery Order Dan MANufacturing

\begin{tabular}{|c|c|c|c|c|c|c|}
\hline & \multicolumn{6}{|c|}{ Persentase Ranking Requirement } \\
\hline & \multicolumn{2}{|l|}{ Fit } & \multicolumn{2}{|c|}{ Partial Fit } & \multicolumn{2}{|l|}{ Gap } \\
\hline & $\begin{array}{l}\text { Total } \\
\text { Require } \\
\text { ment }\end{array}$ & $\begin{array}{l}\text { Persenta } \\
\text { se }\end{array}$ & $\begin{array}{l}\text { Total } \\
\text { Require } \\
\text { ment }\end{array}$ & $\begin{array}{l}\text { Persenta } \\
\text { se }\end{array}$ & $\begin{array}{l}\text { Total } \\
\text { Require } \\
\text { ment }\end{array}$ & $\begin{array}{l}\text { Perse } \\
\text { ntase }\end{array}$ \\
\hline \multicolumn{7}{|c|}{ Ranking Receipts } \\
\hline High & - & - & 1 & $33,3 \%$ & 2 & $66,6 \%$ \\
\hline Medium & 1 & $100 \%$ & - & - & - & - \\
\hline Low & - & - & - & - & - & - \\
\hline \multicolumn{7}{|c|}{ Ranking Delivery Oder } \\
\hline High & - & - & 1 & $50 \%$ & 1 & $50 \%$ \\
\hline Medium & - & - & - & - & - & - \\
\hline Low & 1 & $100 \%$ & - & - & - & - \\
\hline \multicolumn{7}{|c|}{ Ranking Manufacturing } \\
\hline High & - & - & - & - & - & - \\
\hline Medium & - & - & - & - & - & - \\
\hline Low & - & - & 1 & $100 \%$ & - & - \\
\hline
\end{tabular}

3. Failure Mode and Affect Analysis (FMEA)

Penelitian ini, selanjutnya dilakukan analisis risiko (risk analysis) menggunakan analisis FMEA dari hasil laporan penilaian fit/gap analysis yang mempunyai nilai degree of fit setiap kebutuhan utama bisnis (requirement). Penilaian FMEA dibagi menjadi tiga jenis bobot penilaian, yaitu: Severity (S), Occurance (O), dan Detection (D), dimana setiap bobot penilaian memiliki analysis report terhadap fungsi proses yang akan menghasilkan nilai Risk Priority Number (RPN) untuk memprioritaskan tingkat kegagalan yang perlu segera ditangani dengan rekomendasi solusi pada sistem. Berikut adalah tabel laporan penilain analisis FMEA pada setiap fungsi proses pada kebutuhan utama bisnis. Silahkan cermati Tabel 2.

Tabel 2. Laporan Fmea Pada Proses Receipts, Delivery Order Dan Manufacturing

\begin{tabular}{lcccccccc}
\hline \multicolumn{1}{c}{ Potential Failure Mode \& Analysis } & \multicolumn{5}{c}{ Action Results } \\
\hline \multicolumn{1}{c}{ Process } & $\mathrm{S}$ & $\mathrm{O}$ & $\mathrm{D}$ & $\mathrm{RPN}$ & $\mathrm{S}$ & $\mathrm{O}$ & $\mathrm{D}$ & $\mathrm{RPN}$ \\
\hline $\begin{array}{l}\text { Tracking system kurir dari vendor } \\
5\end{array}$ & 8 & 2 & 80 & 3 & 4 & 1 & 12 \\
\hline $\begin{array}{l}\text { Notifikasi push email untuk } \\
\text { receipt barang }\end{array}$ & 10 & 7 & 3 & 210 & 2 & 1 & 1 & 2 \\
\hline $\begin{array}{l}\text { Update stock barang masuk } \\
\text { otomatis }\end{array}$ & 7 & 8 & 8 & 448 & 2 & 3 & 4 & 24 \\
\hline $\begin{array}{l}\text { Update stock barang keluar } \\
\text { otomatis }\end{array}$ & 7 & 8 & 8 & 448 & 2 & 3 & 4 & 24 \\
\hline Tracking System & 5 & 8 & 2 & 80 & 3 & 4 & 1 & 12 \\
\hline Modifikasi menu Bill of Material & 2 & 10 & 4 & 80 & 2 & 1 & 3 & 6 \\
\hline Total S,O,D, dan RPN & 36 & 49 & 35 & 1346 & 11 & 15 & 13 & 80 \\
\hline
\end{tabular}


Hasil analisis risiko menggunakan metode FMEA, terdapat enam proses user requirement yang berkondisi Partial Fit dan Gap, yang mempunyai potensi timbulnya kegagalan. Namun dari potensi tersebut teridentifikasi dua proses yang mempunyai nilai RPN tertinggi, yaitu proses update stock barang masuk otomatis yang terdapat pada Proses Receipts dan update stock barang keluar otomatis yang terdapat pada Proses Delivery Order.

Sehingga dalam penelitian ini, dapat disimpulkan bahwa hasil analisis risiko menggunakan FMEA mampu secara efektif mendeteksi potensi kegagalan dan memberikan rekomendasi penyelesaian masalah. Selain itu dapat ditentukan Gap Resolution dengan resolusi Make the Business Fit the Package, yaitu dengan menggunakan solusi pengembangan (enhancement) dan membuat fitur baru (add-on) untuk menghilangkan kesenjangan sistem berjalan yang diganti dengan proses sistem baru dan Customization as a Last Resort, yaitu dengan membangun fungsionalitas baru di luar sistem.

4. Hasil Perancangan Proses Bisnis menggunakan UML

\subsection{Usecase Diagram}

Use case diagram merupakan titik awal yang baik dalam memahami dan menganalisis kebutuhan sistem pada saat perancangan. Berdasarkan Gambar 4, maka use case diagram Inventory PT Otka, terdiri dari empat actor, yaitu: Otka, Otka Manufacturer, Vendor dan Client. Selain itu, use case diagram ini juga memiliki empat use case, yaitu: receipts, quality control, delivery order dan manufacturing.

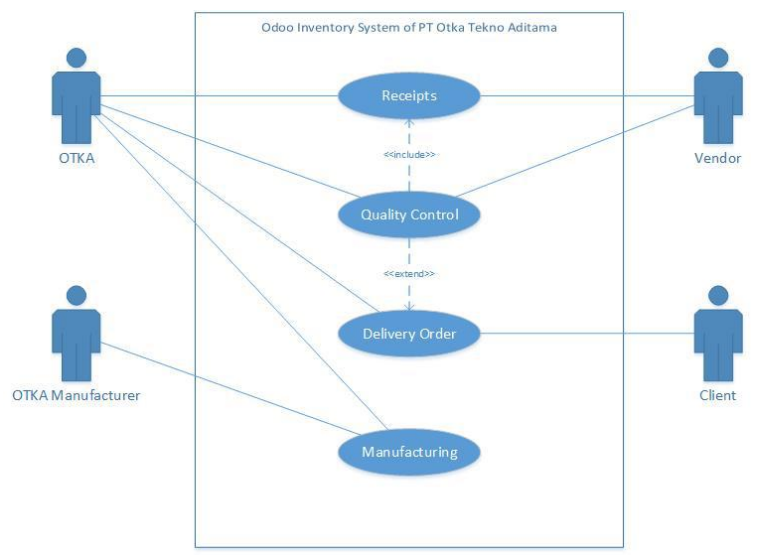

Gambar 4. PERANCANGAN USE CASE DIAGRAM

\subsection{Usecase scenario, Activity Diagram, dan Sequence Diagram}

Merujuk aturan konsistensi aturan UML[10],[14], maka terdapat keterkaitan penjelasan dan fungsi antara use case scenario, activity diagram, dan sequence diagram. Pada use case scenario, dibuat berdasarkan setiap use case yang terdapat pada use case diagram. Demikian pula untuk setiap activity diagram, yang dibuat berdasarkan setiap use case. Keterkaitan untuk sequence diagram, adalah setiap use case scenario tersebut dibuat berdasarkan sequence diagram[14]. Dengan demikian, untuk penamaan komponen pada ketiga diagram tersebut, sebaiknya memiliki 
INTENSIF, Vol.3 No.2 August 2019

ISSN: 2580-409X (Print) / 2549-6824 (Online)

DOI: https://doi.org/10.29407/intensif.v3i2.12697

keterkaitan nama yang sama sebagai identifikasi setiap diagramnya, yaitu: receipts, quality control, delivery order dan manufacturing.

Terdapat empat activity diagram dan empat sequence diagram, penelitian ini yang terdiri dari receipts, quality control, delivery order dan manufacturing. Berikut ini, adalah salah satu dari activity diagram dan sequence diagram tersebut. Silahkan cermati gambar 5 dan gambar 6 .

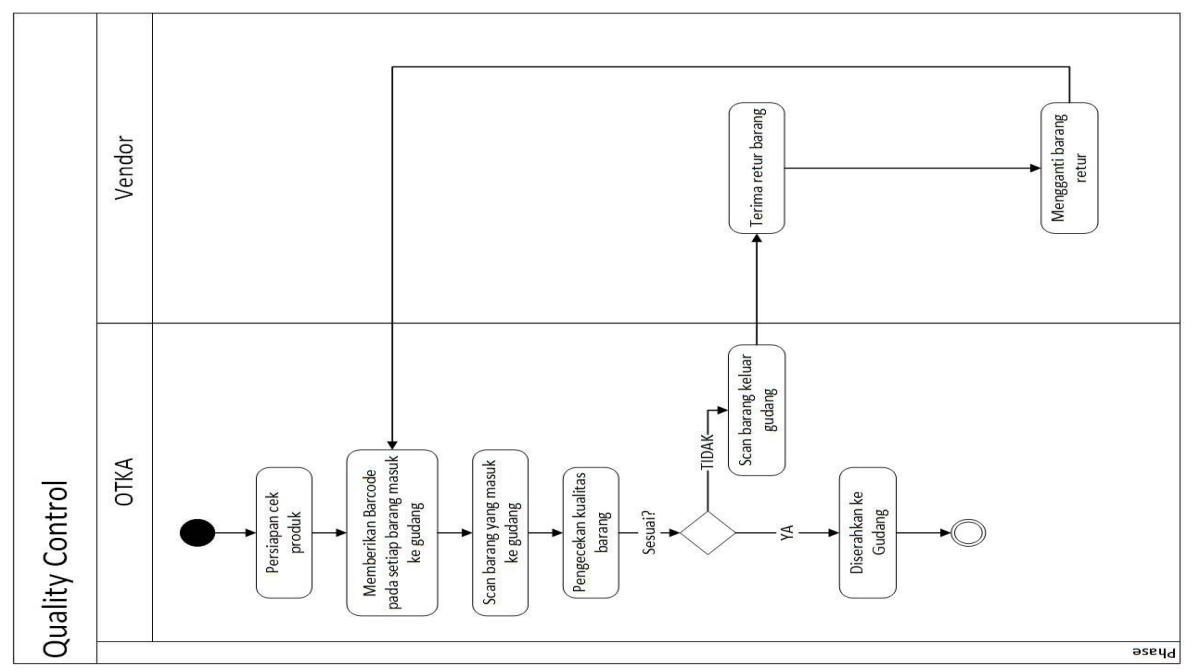

Gambar 5. PERANCANGAN ACTIVITY DiagRaM PROSES QUALITY CONTROL

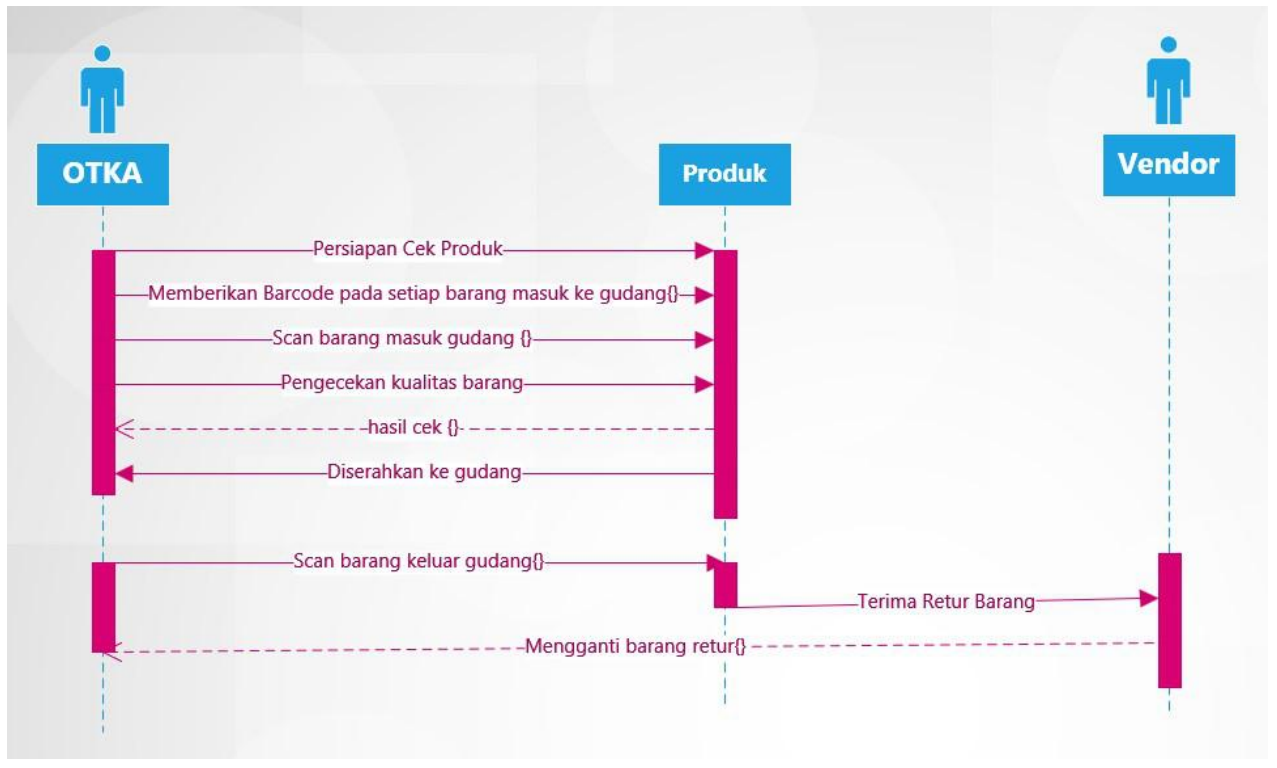

Gambar 6. PERANCANGan SEQUENCE DIAGRAM PROSES QUALITY CONTROL 


\subsection{Class Diagram}

Merujuk aturan notasi mengenai konsistensi pada UML [14], maka Class diagram dibuat berdasarkan keberadaan use case diagram dan sequence diagram, sehingga menghasilkan tujuh Class, yaitu: Otka, Vendor, Client, Otka Manufacturer, Kurir, Produk dan System Database Silahkan cermati Gambar 7.

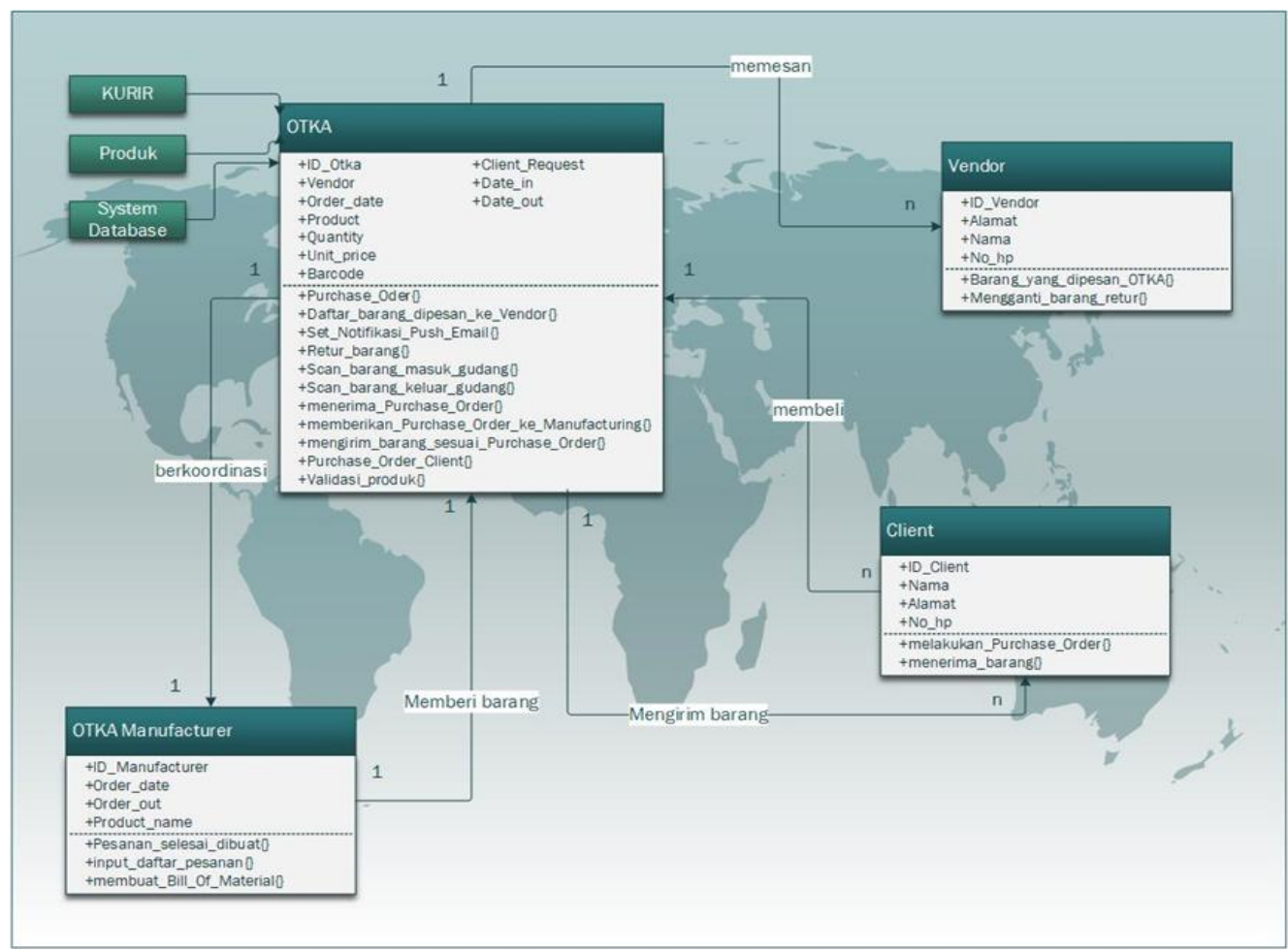

Gambar 7. PERANCANGAN CLASS DIAGRAM INVENTORY PT OTKA

\section{Rancangan Mock up User Interface}

Melalui metodologi UML, para pengembang cukup menggunakan satu metodologi dari tahap analisis hingga perancangan. Hal ini tidak bisa dilakukan dalam metodologi pengembangan terstruktur. Dengan perkembangan masa kini ke arah aplikasi GUI (Graphical User Interface), UML juga memungkinkan perancangan komponen antarmuka pengguna (User Interface)[15].

Terdapat empat mock up user interface proses bisnis inventory pada penelitian ini yang terdiri dari receipts, quality control, delivery order dan manufacturing. Berikut ini adalah salah satu dari mock up user interface tersebut. Silahkan cermati Gambar 8. 
INTENSIF, Vol.3 No.2 August 2019

ISSN: 2580-409X (Print) / 2549-6824 (Online)

DOI: https://doi.org/10.29407/intensif.v3i2.12697

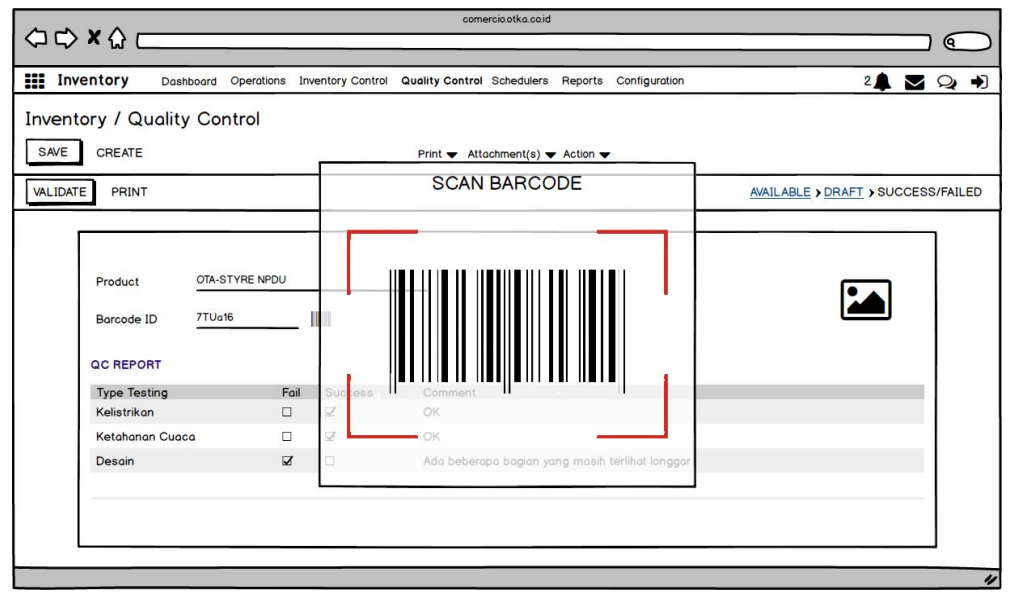

Gambar 8. RANCANGAN CLASS DIAGRAM INVENTORY PT OTKA

\section{KESIMPULAN DAN SARAN}

Berdasarkan hasil analisa Fit/Gap Analysis dapat disimpulkan bahwa, sistem Odoo modul Inventory pada PT. Otka Tekno Aditama belum diimplementasikan dengan maksimal oleh perusahaan dalam rangka mendukung proses bisnis. Hasil analisis risiko dengan FMEA, proses yang mempunyai nilai RPN tertinggi yaitu update stock barang masuk dan update stock barang keluar, maka dalam penelitian ini mendapat kesimpulan bahwa resolusi kesenjangan sistem yang menimbulkan potensi kegagalan disimpulkan "Make the Business Fit the Package" yaitu melakukan pengembangan (enhancement) dan tambahan (add-on) fitur sebagai solusi untuk meminimalkan gap yang terjadi dan "Customization as a Last Resort", yaitu dengan membangun fungsionalitas baru di luar sistem. Tambahan fitur yang digambarkan dengan Unified Modelling Languange (UML), yaitu adanya penambahan aktor "OTKA Manufacturer" dan proses "Quality Control', yang membantu perusahaan untuk update barang Gudang secara otomatis. Saran yang diberikan dari hasil penelitian ini, yaitu PT. Otka Tekno Aditama sebaiknya menggunakan fungsi dari rekomendasi yang diberikan untuk mengoptimalkan penggunaan sistem Odoo dan diperlukan penelitan lanjut dari rekomendasi yang telah dirumuskan untuk mengidentifikasi potensi risiko dan kegagalan lanjutan ketika solusi telah diterapkan pada modul Inventory.

\section{DAFTAR PUSTAKA}

[1] J. A. O’Brien and G. M. Marakas, "Enterprise Business Systems, p. 304," Manag. Inf. Syst. McGraw-Hill/Irwin, 2009.

[2] P. Lech, "Implementation of an ERP system : A case study of a full-scope SAP project," Finans. J. Manag. Financ., vol. 14, no. 1, pp. 49-64, 2016.

[3] L. S. Lipol and J. Haq, "Risk Analysis Method : FMEA / FMECA in the Organizations," 
Int. J. Basic Appl. Sci. IJBAS-IJENS, vol. 11, no. October, pp. 49-57, 2011.

[4] A. Sachdeva, K. Dinesh, and P. Kumar, "Multi-Factor Failure Mode Critically Analysis Using TOPSIS," J. Ind. Eng. Int., vol. 5, no. 8, pp. 1-9, 2009.

[5] M. A. Salam, M. M. Billal, M. M. Rahman, and M. A. Islam, "An evaluation of failure modes and effect analysis for a battery manufacturing industry," Int. Conf. Mech. Ind. Mater. Eng. 2015, no. 11-13 Dec 2015, pp. 0-6, 2015.

[6] R. P. Perdana and E. Yuliawati, "Integrasi Metode FMEA Dan Topsis Untuk Menganalisis Risiko Kecelakaan Pada Proses Frame And Fork Welding," Spektrum Ind., vol. 12, pp. 43-52, 2014.

[7] D. Pajk and A. Kovacic, "FIT GAP ANALYSIS - THE ROLE OF BUSINESS PROCESS REFERENCE MODELS,”Econ. Bus. Rev. Cent. South - East. Eur., 2013.

[8] M. I. Wibisono and M. Awaludin, "Evaluasi Integrasi Sistem Enterprise Dengan SAP ECC 6.0 Pada Perusahaan FMCG,” Pros. SINTAK, pp. 237-243, 2017.

[9] K. Riplová, “TOOL OF RISK MANAGEMENT: FAILURE MODE AND EFFECTS ANALYSIS AND FAILURE MODES, EFFECTS AND CRITICALITY ANALYSIS," Res. Gate, vol. 5, no. 1, pp. 111-120, Feb. 2007.

[10] S. Uke, A. Mahajan, and R. C. Thool, "UML Modeling of Physical and Data Link Layer Security Attacks in WSN," Int. J. Comput. Appl., vol. 70, no. 11, pp. 25-28, 2013.

[11] Haviluddin, "Memahami Penggunaan UML (Unified Modelling Language)," J. Inform. Mulawarman, vol. 6, no. 1, 2011.

[12] Kenneth E. Kendall; Julie E. Kendall, System Analysis and Design, 8th ed. New Jersey: Pearson, 2006.

[13] Sugiyono, "Teknik Pengumpulan Data," in Metode Penelitian Kuantitatif, Kualitatif dan $R \& D, 2014$.

[14] R. Rundupandang and Y. Priyadi, "Perancangan UML Sebagai Rekomendasi Proses Bisnis Berdasarkan BMC Di Geoff Max Bandung," J. Wacana Ekon., vol. 18, no. 1, pp. $13-21,2018$.

[15] I. Zufria, "Pemodelan Berbasis UML ( Unified Modeling Language ) dengan Strategi Teknik Orientasi Objek User Centered Design ( UCD ...," Research Gate, 2013. [Online]. Available:

https://www.researchgate.net/publication/306037464_Pemodelan_Berbasis_UML_Unifi ed_Modeling_Language_dengan_Strategi_Teknik_Orientasi_Objek_User_Centered_De signUCD_dalam_Sistem_Administrasi_Pendidikan. [Accessed: 20-Jan-2019]. 